\title{
Agroinfiltration Is a Versatile Tool That Facilitates Comparative Analyses of Avr9/Cf-9-Induced and Avr4/Cf-4-Induced Necrosis
}

\author{
Renier A. L. Van der Hoorn, Franck Laurent, Ronelle Roth, and Pierre J. G. M. De Wit \\ Laboratory of Phytopathology, Wageningen University, Binnenhaven 9, 6709 PD Wageningen, \\ The Netherlands \\ Accepted 28 December 1999.
}

\begin{abstract}
The avirulence genes Avr9 and Avr4 from the fungal tomato pathogen Cladosporium fulvum encode extracellular proteins that elicit a hypersensitive response when injected into leaves of tomato plants carrying the matching resistance genes, $C f-9$ and $C f-4$, respectively. We successfully expressed both Avr9 and Avr4 genes in tobacco with the Agrobacterium tumefaciens transient transformation assay (agroinfiltration). In addition, we expressed the matching resistance genes, $C f-9$ and $C f-4$, through agroinfiltration. By combining transient $C f$ gene expression with either transgenic plants expressing one of the gene partners, $\mathrm{Po}$ tato virus $X(\mathrm{PVX})$-mediated Avr gene expression, or elicitor injections, we demonstrated that agroinfiltration is a reliable and versatile tool to study $A v r / C f$-mediated recognition. Significantly, agroinfiltration can be used to quantify and compare $A v r / C f$-induced responses. Comparison of different $A v r / C f$-interactions within one tobacco leaf showed that $A v r 9 / C f$-9-induced necrosis developed slower than necrosis induced by Avr4/Cf-4. Quantitative analysis demonstrated that this temporal difference was due to a difference in $A v r$ gene activities. Transient expression of matching $A v r / C f$ gene pairs in a number of plant families indicated that the signal transduction pathway required for $A v r / C f$-induced responses is conserved within solanaceous species. Most non-solanaceous species did not develop specific $A v r / C f$-induced responses. However, coexpression of the $A v r 4 / C f-4$ gene pair in lettuce resulted in necrosis, providing the first proof that a resistance $(R)$ gene can function in a different plant family.
\end{abstract}

Co-evolution between plants and pathogens has enabled plants to develop effective surveillance systems to recognize pathogens and mount defense responses. Defense responses are diverse and usually include a hypersensitive response (HR) where tissue surrounding the infection site becomes necrotic (Hammond-Kosack and Jones 1996). The plant surveillance system has a genetic basis, involving dominant resistance $(R)$ genes that confer the ability to recognize invading

Corresponding author: Pierre De Wit; Telephone: +31-317-483130; Fax: +31-317-483412; E-mail: Pierre.deWit@Medew.FYTO.WAU.NL

Present address of Franck Laurent: Institut de Biotechnologie des Plantes, Université Paris Sud, Bat. 630, 91405 Orsay Cedex, France. pathogens carrying matching avirulence (Avr) genes. Tremendous efforts in the past decade have resulted in the cloning of many $R$ and $A v r$ genes.

$R$ gene products can be broadly classified into two groups based on their predicted cellular location (De Wit 1997; Jones and Jones 1997; Parker and Coleman 1997). The first and largest group of $\mathrm{R}$ proteins is cytoplasmic and the members often contain leucine-rich repeats (LRRs) and nucleotide binding sites (NBSs). Members of this group have been cloned from flax (e.g., $L$ genes), lettuce (Dm genes), Arabidopsis thaliana (e.g., RPP genes), several solanaceous species (e.g., $N, \mathrm{Mi}, \mathrm{Gpa}, \mathrm{Bs} 2$ ), and monocots (Xal and $\mathrm{Cre} 3$ ) (reviewed by Van der Biezen and Jones 1998). The Pto gene, which encodes a serine-threonine kinase, is the only cytoplasmic $\mathrm{R}$ protein within this group that lacks LRRs and NBSs. The second and smaller group of $R$ genes encodes putative plasma membraneanchored proteins. They all carry extracellular LRR domains and members of this group have been cloned from rice (Xa21), sugar beet $\left(H S^{P r o-1}\right)$, and tomato (e.g., $C f-9$ and $C f-4$ ) (Cai et al. 1997; Jones and Jones 1997).

Proteins that are encoded by Avr genes share less common features (Culver et al. 1991; Laugé and De Wit 1998; Van den Ackerveken and Bonas 1997). Their predicted cellular location often fits with that of their matching $R$ gene product. For example, the Avr9 and Avr4 genes from the biotrophic leaf mold fungus Cladosporium fulvum encode elicitor proteins that are secreted into the tomato leaf apoplast. Injection of these elicitor proteins into extracellular leaf spaces of tomato plants that carry a matching $C f$ gene is sufficient to trigger an HR (Joosten and De Wit 1999). In contrast, viral and bacterial AVR proteins only elicit an HR when produced in the host cytoplasm and not when injected into leaves (Bonas and Van den Ackerveken 1997). The latter proteins possibly interact with $R$ gene products in the host cytoplasm, as was shown for the AvrPto and Pto proteins (Scofield et al. 1996; Tang et al. 1996).

To improve our understanding of $A v r / C f$ interactions at the molecular level, transient expression with Potato virus $X$ (PVX; Chapman et al. 1992) has been employed to study the effects of mutations in Avr9 and Avr4 genes (Joosten et al. 1997; Kooman-Gersmann et al. 1997). However, transient expression of $C f$ genes through $\mathrm{PVX}$ is constrained by the size of the inserted gene that is allowed in the recombinant virus. In contrast to PVX, Agrobacterium tumefaciens can accom- 
modate large genes and has a broad host range (Bundock and Hooykaas 1998). Transient expression of genes through infiltration of A. tumefaciens cultures into leaf tissue (agroinfiltration) is a quick and easy method to study genes of interest (Kapila et al. 1997; Rossi et al. 1993).

In this report, we demonstrate that $A v r 9$ and $A v r 4$, as well as their large matching $R$ genes $C f-9$ and $C f-4$, respectively, can be successfully expressed by agroinfiltration. We show that agroinfiltration can be combined with either transgenic plants expressing one of the matching gene partners, PVX-mediated $A v r$ gene expression, or injection of elicitor protein. In addition, we used agroinfiltration for quantitative analysis and comparison of different $A v r / C f$-induced responses in tobacco and other plant species. Although initial results indicated that Avr $9 / C f$-9-induced necrosis developed slower than that induced by $A v r 4 / C f-4$, we demonstrate that this temporal difference is due to differences in Avr gene activities. Transient expression of matching gene partners in a number of plant species revealed that the signal transduction pathway required for $A v r / C f$-induced responses is conserved within solanaceous species. Most non-solanaceous species did not show specific $A v r / C f$-induced responses, with the exception of lettuce, in which necrosis was induced by co-expression of the $A v r 4 / C f-4$ gene pair.

\section{RESULTS}

Transient expression of $\boldsymbol{A v r}$ and $\boldsymbol{C} \boldsymbol{f}$ genes in tobacco.

As tobacco can be transformed easily and $C f-9$ transgenic tobacco was found to respond with an HR upon injection with AVR9 protein (Hammond-Kosack et al. 1998), we used Cf-9transgenic tobacco to transiently express the Avr9 gene through agroinfiltration. When young, fully expanded leaves were infiltrated with A. tumefaciens carrying pAvr9 (Fig. 1), the entire infiltrated area became necrotic (Fig. 2A). Leaf tissue started to collapse at 1 day post infiltration (dpi) and had developed into a yellow-brown sector by $7 \mathrm{dpi}$. In wild-type tobacco no necrosis occurred upon transient $A v r 9$ expression (Fig. 2B). Similarly, transient expression of Avr4 resulted in necrotic sectors in $C f-4$ transgenic tobacco but not in wildtype tobacco (data not shown). A major advantage of agroinfiltration is that the T-DNA can accommodate large genes such as the $2.6-\mathrm{kb}$ open reading frame (ORF) of the $C f-9$ resistance gene. Transient expression of $C f-9$ in $A v r 9$ transgenic tobacco (Hammond-Kosack et al. 1994) resulted in necrosis (Fig. 2C), while no necrotic responses were induced in wildtype tobacco (Fig. 2B). Together, these results demonstrate that genes that encode the extracellular elicitors AVR9 or AVR4 and the large, extracellular, membrane-anchored Cf9 protein can be successfully expressed in tobacco through agroinfiltration.

Both Avr9 and Avr4 have been transiently expressed through the PVX expression system (Hammond-Kosack et al. 1995; Joosten et al. 1997). To test whether transient $C f$ gene expression through agroinfiltration can be combined with PVX-mediated $A v r$ gene expression, wild-type tobacco plants were inoculated with PVX::Avr9, PVX::Avr4, or wild-type PVX. Two weeks after PVX inoculation, A. tumefaciens carrying pCf9 or pCf4 (Fig. 1) was infiltrated into leaves that showed clear mosaic symptoms. Necrosis only appeared in sectors where matching gene pairs were expressed (Fig. 2D).
This indicates that agroinfiltration of both $C f-9$ and $C f-4$ genes can successfully be combined with PVX-mediated expression of the matching Avr gene.

Elicitor peptides AVR9 and AVR4 were originally purified from apoplastic fluids (AFs) isolated from compatible C. fulvum-tomato interactions (Scholtens-Toma and De Wit 1988; Joosten et al. 1994). In addition to these proteins, AFs contain many other fungal elicitor proteins. To test the specificity of tobacco leaves that transiently express $C f-9$ or $C f-4$ for AVR9 and AVR4 detection, respectively, crude AFs were injected 1 day after agroinfiltration of wild-type tobacco with $\mathrm{pCf} 9$ or pCf4. Necrotic responses were only detected in leaf sectors that were injected with AFs containing a matching elicitor (Fig. 2E), indicating that tobacco tissue that transiently expresses $C f$ genes has the same specificity for recognition of AVR proteins as tomato genotypes containing the native $C f$ genes.

Moneymaker-Cf9 (MM-Cf9) tomato leaves are very sensitive to injection of AVR9 elicitor protein, as concentrations of AVR9 as low as $300 \mathrm{nM}$ result in a clear necrotic response (Kooman-Gersmann et al. 1998). When tobacco leaves that transiently express the $C f-9$ gene were injected with a concentration series of AVR9 peptide, concentrations as low as 10 $\mathrm{nM}$ resulted in a clear necrotic response above background (Fig. 2F). As expected, only background responses developed in tissue that transiently expressed $C f-4$ (Fig. 2F). This suggests that transient $C f-9$ expression levels in tobacco are high enough to detect low concentrations of AVR9.

\section{Comparison of necrotic responses induced by} transient expression of $A v r 9 / C f-9$ and $A v r 4 / C f-4$ gene pairs.

To date, comparisons between Avr $9 / C f-9$ - and $A v r 4 / C f-4$ induced responses have not been conclusive, due to developmental and/or genetic differences between plants that harbor

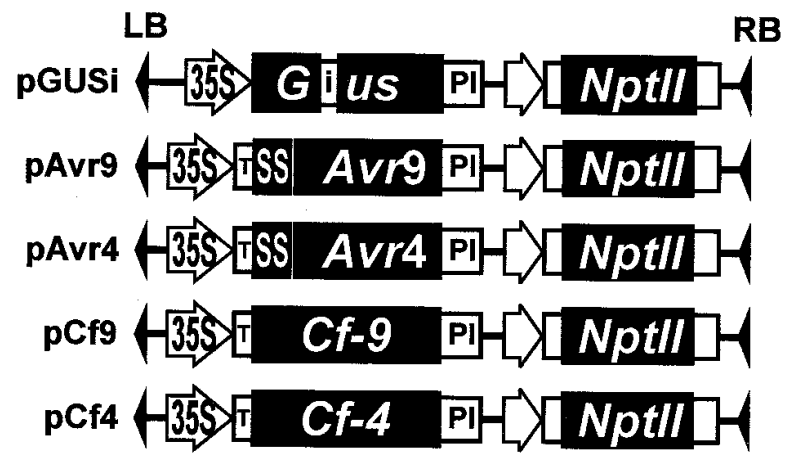

Fig. 1. Schematic representation of the T-DNAs present on the five binary plasmids used in this study. Each binary plasmid is named after the gene that is present on the T-DNA. The $\beta$-glucuronidase (gus) gene is interrupted by an intron, which excludes $A$. tumefaciens-derived gus expression (Vancanneyt et al. 1990). Avr9 and Avr4 are fused to the tobacco pathogenesis-related PRIa signal sequence to ensure extracellular targeting. Symbols: black boxes, ORFs; open boxes, untranslated regions; open arrows, promoters; black triangles, T-DNA borders. Abbreviations: Gus, gene encoding $\beta$-glucuronidase; i, intron; $A v r 9$, ORF encoding 28 amino acid mature AVR9 protein; Avr4, ORF encoding 86 amino acid mature AVR4 protein; SS, signal sequence from tobacco pathogenesis-related PRla gene; $C f$-9, ORF encoding wild-type Cf9; $C f$ 4 , ORF encoding wild-type $\mathrm{Cf} 4 ; 35 \mathrm{~S}$, Cauliflower mosaic virus (CaMV) $35 \mathrm{~S}$ promoter; T, omega Tobacco mosaic virus (TMV) leader; PI, potato proteinase inhibitor-II polyadenylation region; RB, right border of TDNA; LB, left border of T-DNA; NptII, neomycin-phosphotransferase II. 
the different $C f$ genes. The ability to express $C f$ genes simultaneously in the same leaf tissue enabled us for the first time to compare induced responses within the same leaf. Therefore, A. tumefaciens cultures carrying the $\mathrm{pAvr}$ and $\mathrm{pCf}$ plasmids were mixed in a 1:1 ratio and infiltrated into wild-type tobacco leaves. Necrosis only developed in leaf sectors that expressed matching gene pairs (Fig. 3A). Clear differences between $A v r 9 / C f-9$ - and $A v r 4 / C f$-4-induced responses were observed. Tissue collapse induced by expression of the Avr $9 / C f-9$ gene pair occurred 1 day later than that induced by the $A v r 4 / C f-4$ gene pair (Fig. 3B). Typically, Avr9/Cf-9induced necrosis only started to develop after the entire $A v r 4 / C f$-4-expressing area had collapsed. Although the pattern of tissue collapse was identical, the Avr $9 / C f$-9-induced collapse was preceded by weak chlorosis. The color of the ne- crotic sector resulting from $A v r 9 / C f-9$ co-expression gradually turned dark brown (Fig. 3A), suggesting that there was time for the accumulation of phenolic compounds.

Although the binary constructs used in this study were comparable, differences observed in the speed of necrotic responses could be caused by differences in activities of the pAvr or pCf plasmids upon agroinfiltration. We, therefore, quantified responses induced upon infiltration of a dilution series of A. tumefaciens carrying pAvr and pCf (Fig. 3C and D). To exclude differences between culture densities, cultures of equal density that carry matching pAvr and pCf plasmids were mixed in different ratios. The percentage of infiltrated leaf area that had become necrotic at 7 dpi was measured and plotted against the percentage of $A$. tumefaciens cultures that carry pAvr and pCf. The percentage of the culture containing
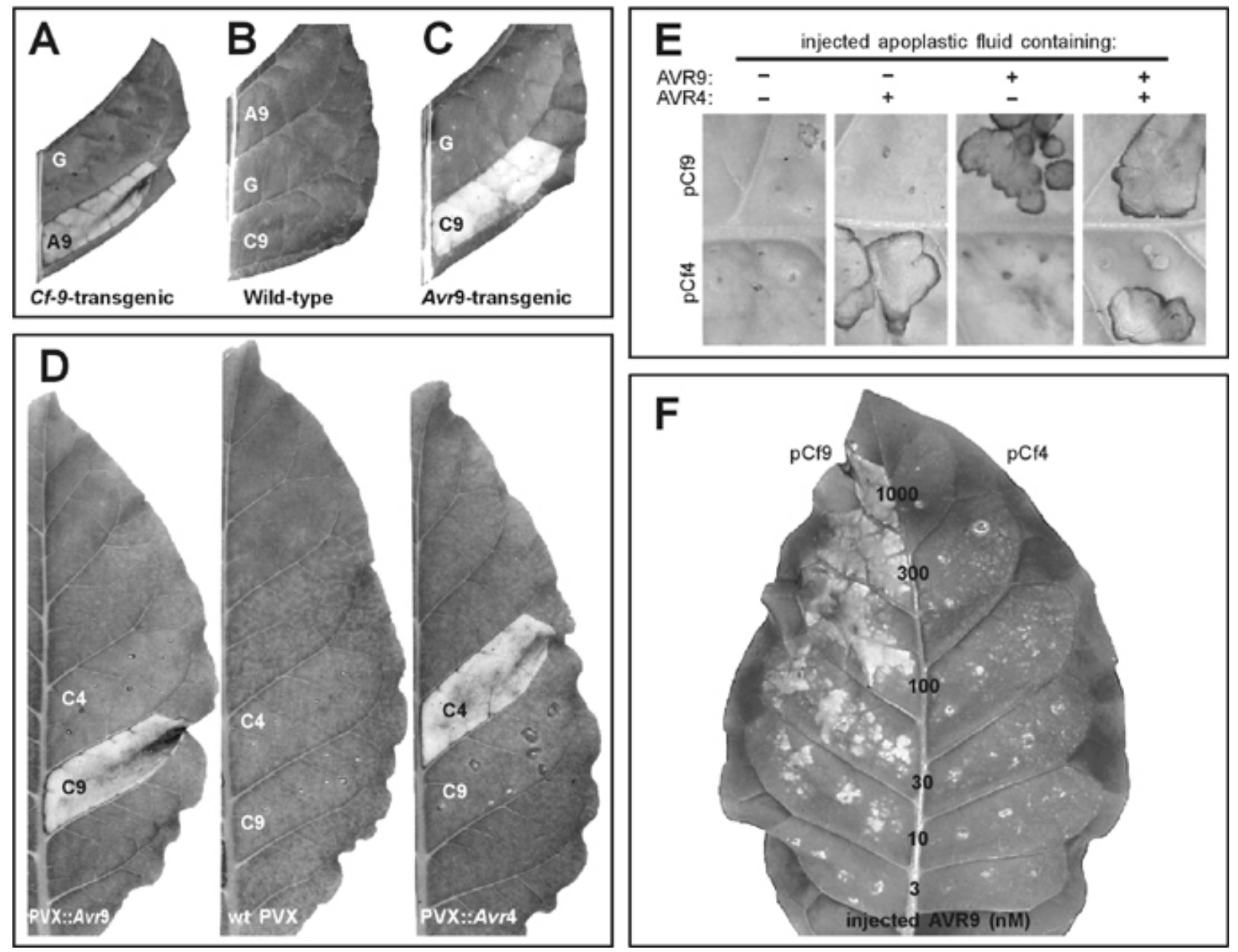

Fig. 2. Transient expression of $A v r$ and $C f$ genes in tobacco leaves. Agrobacterium tumefaciens carrying pGUSi (G), pAvr9 (A9), pCf9 (C9), or pCf4 (C4) was infiltrated into young, fully expanded leaves of 6-week-old tobacco plants. Photographs were taken at 7 days post infiltration (dpi). A, Transient expression of the $\beta$-glucuronidase ( $g u s$ ) gene and $A v r 9$ in $C f-9$ transgenic tobacco. B, Transient expression of $A v r 9$, gus, and $C f-9$ in wild-type tobacco. C, Transient expression of gus and $C f-9$ in $A v r 9$ transgenic tobacco. D, Transient $C f$ gene expression in Potato virus $X$ (PVX)-inoculated, wildtype tobacco plants. Two weeks post inoculation, cultures of A. tumefaciens carrying pCf9 or pCf4 were infiltrated into young, fully expanded leaves that showed mosaic symptoms caused by PVX. E, Injection of apoplastic fluids (AFs), isolated from different compatible $C$. fulvum-tomato interactions into tobacco leaves at 1 dpi with A. tumefaciens containing pCf9 or pCf4. AFs were isolated from tomato cultivar Moneymaker Cf0 inoculated with $C$. fulvum race 2.4.5.9.11 (MM-Cf0/race 2.4.5.9.11) (lacks AVR9 and AVR4, first panel), MM-Cf5/race 2.5.9 (lacks AVR9, second panel), MM-Cf4/race 2.4.8.11 (lacks AVR4, third panel), and MM-Cf0/race 5 (contains both AVR9 and AVR4, fourth panel). F, Injection of a concentration series of AVR9 protein, performed at 1 dpi with A. tumefaciens containing pCf9 (left leaf half) or pCf4 (right leaf half) into wild-type tobacco leaves. Photograph was taken at 7 dpi. 
pCf that induced $50 \%$ necrosis $\left(\mathrm{NC}^{50}\right)$ of the infiltrated leaf area was calculated from two independent experiments. $\mathrm{NC}^{50}$ values for pCf9 were 1.86 and $3.74 \%$, respectively, whereas $\mathrm{NC}^{50}$ values for pCf4 were calculated as 1.38 and $4.92 \%$, respectively (Fig. 3C). This indicates that pCf9 and pCf4 have comparable activities. $\mathrm{NC}^{50}$ values for $\mathrm{pAvr} 9$ and $\mathrm{pAvr} 4$ were calculated as $2.56 \pm 0.88 \%$ and $0.27 \pm 0.12 \%$, respectively $(n$ $=4$, Fig. 3D), indicating that pAvr9 has a 10-fold lower activity, compared with pAvr4. Significantly, at concentrations corresponding to these $\mathrm{NC}^{50}$ values no difference in timing between Avr9/Cf-9- and Avr4/Cf-4-induced necrosis was observed (data not shown). These data indicate that the temporal differences in necrotic responses induced by $A v r 9 / C f-9$ and $A v r 4 / C f-4$ gene pairs when cultures were mixed in a 1:1 ratio are caused by differences in activities between pAvr plasmids upon agroinfiltration.

\section{Transient expression of matching $A v r / C f$ gene pairs in different plant families.}

The extensive homology between $R$ gene products suggests that signal transduction cascades that lead to disease resistance are highly conserved between plant families. To examine whether species other than tobacco and tomato have the signal transduction components that are required for Avr/Cfinduced responses, we transiently co-expressed matching gene pairs in a number of different plant species. Transient expression of the $\beta$-glucuronidase (gus) gene served as an indication of the transformation efficiency and the level of gene expression. Specific responses that were induced by co-expressing matching gene pairs were compared with aspecific responses induced by gus expression and by co-expressing non-matching gene pairs.

Some plant species were difficult to infiltrate (e.g., soybean, rice, and maize) whereas others showed very low levels of GUS staining (e.g., sugar beet, broad bean, and Brussels sprouts) (data not shown). Plant species that showed severe background responses included tomato, potato, cucumber, and pepper (data not shown). Therefore, agroinfiltration in these plant species remains to be optimized.

Plant species that showed significant GUS staining and low background responses are shown in Table 1. All tobacco cultivars tested showed a strong necrotic response within the entire infiltrated area upon co-expression of matching gene pairs, while aspecific responses remained negligible. As with tobacco cv. Petite Havana SR1, transient co-expression of the $A v r 9 / C f-9$ gene pair in other tobacco cultivars always resulted
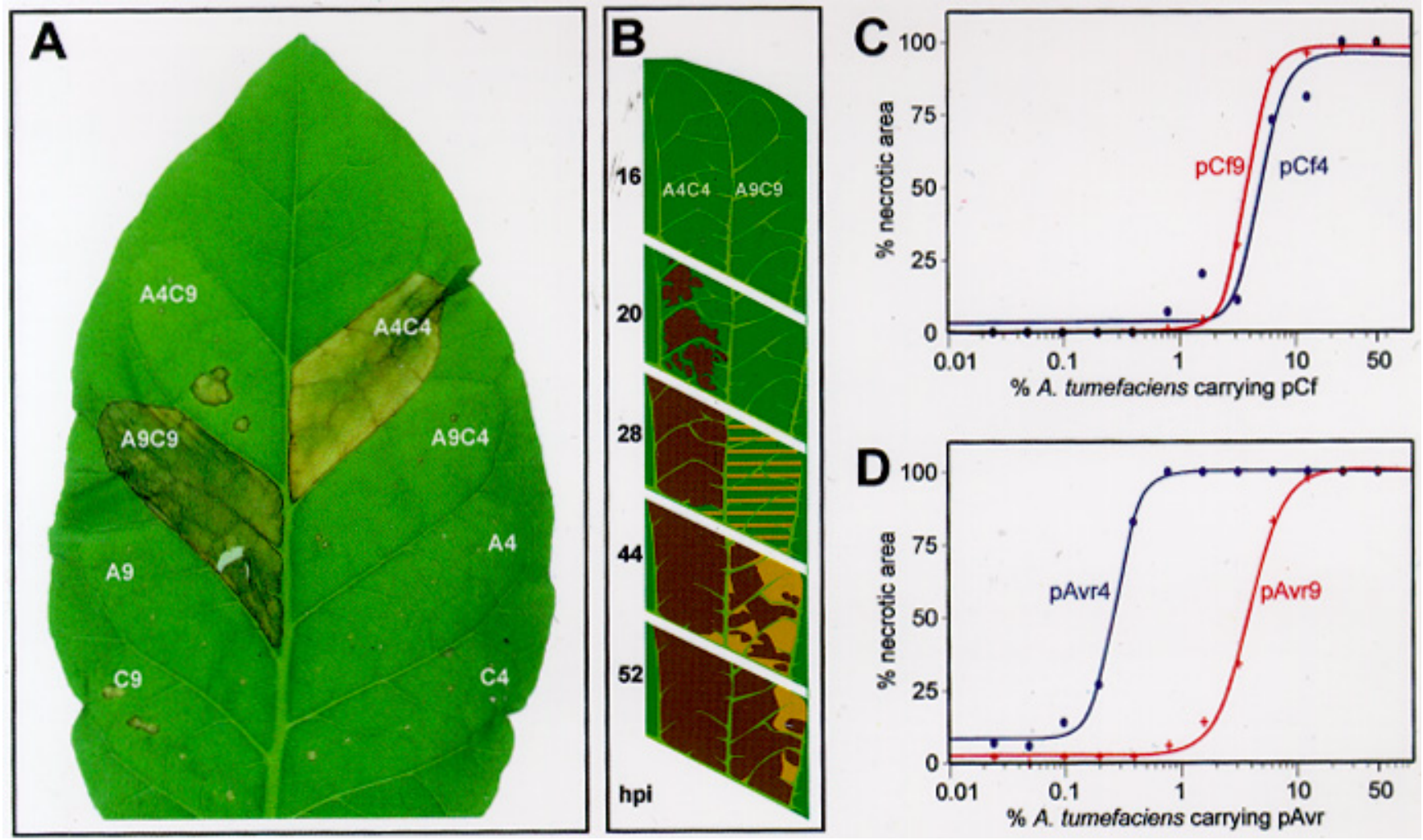

Fig. 3. Comparison necrosis induced by different matching $A v r / C f$ gene pairs. A, Transient expression and co-expression of $A v r 9$ (A9), $C f-9$ (C9), Avr4 (A4), and $C f-4(\mathrm{C} 4)$ in wild-type tobacco. For transient co-expression, Agrobacterium tumefaciens cultures were mixed in a 1:1 ratio and infiltrated. Photograph was taken at 7 days post infiltration (dpi). B, Drawing representing development of responses induced by co-expression of $A v r 9 / C f-9$ or Avr4/Cf-4 gene pairs in wild-type tobacco. Drawings were made of the same leaf at different hours post infiltration (hpi) and show intact tissue (green), strong chlorotic areas (yellow), weak chlorotic areas (yellow stripes), and areas with collapsed tissue (brown). C, Quantification of necrosis induced by transient $C f$ gene expression. A. tumefaciens carrying pCf was diluted with A. tumefaciens carrying the matching pAvr and infiltrated into wild-type tobacco leaves. pCf9 (+) and pCf4 $(\bullet)$ dilution series were infiltrated into opposite leaf halves. Percentage of infiltrated leaf area that had become necrotic at $7 \mathrm{dpi}$ was measured and plotted against concentration of A. tumefaciens that carries pCf. D, Quantification of necrosis induced by transient Avr gene expression. A. tumefaciens carrying pAvr was diluted with A. tumefaciens carrying matching pCf and infiltrated into wild-type tobacco leaves. pAvr9 (+) and pAvr4 $(\bullet)$ dilution series were infiltrated into opposite leaf halves. Percentage of infiltrated leaf area that had become necrotic at 7 dpi was measured and plotted against concentration of A. tumefaciens that carries pAvr. $\mathbf{C}$ and $\mathbf{D}$, One representative experiment is shown in each. 
in a more dark brown necrotic sector than co-expression of the Avr4/Cf-4 gene pair. Nicotiana benthamiana and N. plumbaginifolia showed specific chlorotic responses, often with a necrotic center. In $N$. clevelandii, specific necrotic responses were only visible at the site of infiltration, whereas GUS staining was also present at more distal sites. In N. glutinosa, specific necrosis developed within 7 days, whereas aspecific necrosis developed later. In Petunia hybrida, a specific chlorotic response developed with both gene pairs. The observation that all solanaceous species that were tested showed necrotic or chlorotic responses upon co-expression of $A v r 9 / C f$ 9 and $A v r 4 / C f-4$ suggests that components that are required for $A v r / C f$-induced responses are conserved within this family.

Transient expression of $A v r / C f$ gene pairs in the non-solanaceous species $A$. thaliana, radish, lupine, pea, and flax did not induce any chlorotic or necrotic responses (Table 1), even though significant GUS staining and low aspecific responses were observed (Fig. 4A). In lettuce, which showed clear GUS staining and low aspecific responses, a necrotic response was induced upon co-expression of the Avr4/Cf-4 gene pair, whereas expression of $A v r 4$ and $C f-4$ in nonmatching combi- nations with $C f-9$ and $A v r 9$, respectively, did not induce necrosis (Fig. 4B). Surprisingly, co-expression of the Avr $9 / C f-9$ gene pair in lettuce did not result in necrosis under the conditions tested.

\section{DISCUSSION}

\section{Transient expression of $A v r / C f$ gene pairs.}

The gene pairs investigated in this study are derived from the fungal pathogen $C$. fulvum and its only host, tomato. As the fungus grows extracellularly, it is expected that secreted AVR proteins are perceived on the tomato plasma membrane via $R$ gene products (Joosten and De Wit. 1999). By demonstrating that specific necrosis occurs upon transient expression of matching Avr/Cf gene pairs, we have shown for the first time that agroinfiltration can be used to study extracellular perception. Prior to this study, transient expression through agroinfiltration was only used to express the small cytoplasmic R protein Pto (Frederick et al. 1998; Rathjen et al. 1999) and to demonstrate that perception of AvrBs3, AvrPto, Tobacco mosaic virus (TMV)-helicase, and PVX coat protein

Table 1. Transient expression of $\beta$-glucuronidase (gus) and $A v r / C f$ gene pairs in different plant species

\begin{tabular}{|c|c|c|c|c|c|}
\hline \multirow[b]{2}{*}{ Plant species } & \multirow[b]{2}{*}{ Family } & \multicolumn{4}{|c|}{ Induced responses $^{b}$} \\
\hline & & GUS $^{\mathbf{a}}$ & Aspecific & Avr $9 / C f-9$ & $\operatorname{Avr} 4 / C f-4$ \\
\hline Nicotiana tabacum cv. Petit Havana & Solanaceae & +++ & - & +++ & +++ \\
\hline N. tabacum cv. Samsun NN & Solanaceae & +++ & - & +++ & +++ \\
\hline N. tabacum cv. Xanthi & Solanaceae & +++ & - & +++ & +++ \\
\hline N. tabacum cv. White Burley & Solanaceae & +++ & + & +++ & +++ \\
\hline N. benthamiana & Solanaceae & +++ & + & ++ & ++ \\
\hline N. clevelandii & Solanaceae & +++ & - & + & + \\
\hline N. glutinosa & Solanaceae & +++ & ++ & +++ & +++ \\
\hline N. rustica & Solanaceae & ++ & + & ++ & ++ \\
\hline N. plumbaginifolia & Solanaceae & ND & - & + & + \\
\hline Petunia hybrida W115 & Solanaceae & ND & + & ++ & ++ \\
\hline Lactuca sativa (lettuce) & Compositae & +++ & - & - & +++ \\
\hline Arabidopsis thaliana cv. Col-0 & Cruciferae & +++ & - & - & - \\
\hline Raphanus sativus (radish) & Cruciferae & + & - & - & - \\
\hline Lupinus albus (lupine) & Leguminosae & + & - & - & - \\
\hline Pisum sativum (pea) & Leguminosae & ++ & - & - & - \\
\hline Linum usitatissimum (flax) & Linaceae & +++ & - & - & - \\
\hline
\end{tabular}

${ }^{a}$ gus gene expression, as estimated by GUS staining at 7 days post infiltration $(\mathrm{dpi}) ;+=$ low, ++ = moderate, and $+++=$ high gus expression; ND = not determined.

${ }^{\mathrm{b}}$ Induced responses at $7 \mathrm{dpi}$ by transient expression of $A v r 4 / C f-9$, $A v r 9 / C f-4$, or $g u s$ (aspecific responses), $A v r 9 / C f-9$ and $A v r 4 / C f-4$ (specific responses). $-=$ no response, compared with non-infiltrated area; $+=$ weak chlorosis/necrosis; $++=$ moderate chlorosis/necrosis; $+++=$ severe necrosis of entire infiltrated area. Co-expression was done by infiltrating cultures that were mixed in a 1:1 ratio.
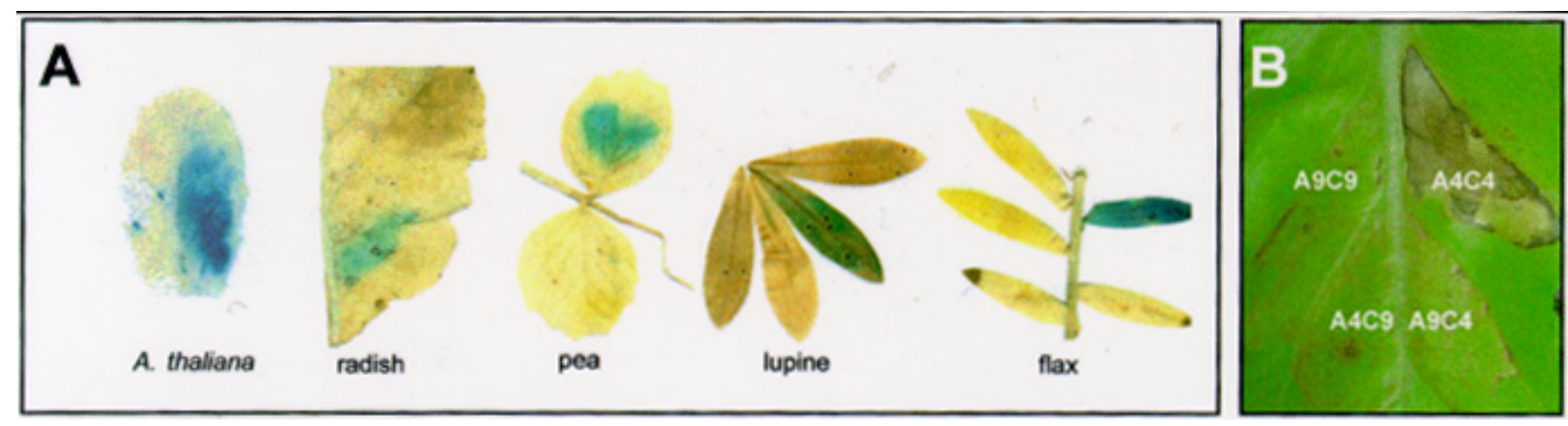

Fig. 4. Expression of $\beta$-glucuronidase ( $g u s)$ and $A v r / C f$ gene pairs in different plant species. A, Transient gus expression in different plant species following agroinfiltration with pGUSi. GUS staining was performed at 7 days post infiltration (dpi). B, Transient co-expression of $A v r 9$ (A9), $C f-9$ (C9), Avr4 (A4), and $C f-4(\mathrm{C} 4)$ in lettuce by infiltration of cultures that were mixed in a 1:1 ratio. Photograph was taken at $7 \mathrm{dpi}$. 
occurs in the cytosol (Abbink et al. 1998; Bendahmane et al. 1999; Erickson et al. 1999; Scofield et al. 1996; Tang et al. 1996; Van den Ackerveken et al. 1996).

Our results demonstrate that $C f$-mediated recognition of $A v r$ gene products is retained when agroinfiltration is combined with established assays, such as transgenic tobacco plants expressing a matching gene partner, PVX-mediated Avr gene expression, or elicitor protein injections. Injection of a dilution series of AVR9 protein into leaves that transiently express $C f$ 9 shows that agroinfiltration is sufficiently sensitive to study $A v r / C f$ interactions. Furthermore, necrosis induced by agroinfiltration of $A v r / C f$ gene pairs can be quantified and can also be used to study $A v r / C f$-induced responses in a large number of plant species. Together, these results indicate that agroinfiltration is a powerful and versatile tool for further studies on $A v r$ and $C f$ gene function.

$R$ gene products are key components in the signal transduction pathway leading to induction of programmed cell death and defense responses that eventually stop invasion of the pathogen. Therefore, overexpression of $R$ genes in the absence of matching elicitors may result in auto-necrosis. For example, overexpression of the Pto gene induced necrosis in the absence of AvrPto (Tang et al. 1999). The pCf constructs used in this study were all driven by a $35 \mathrm{~S}$ promoter to ensure sufficient $C f$ gene expression. Indeed, dilution experiments showed that a culture containing only $2 \%$ pCf-carrying $A$. $t u$ mefaciens is sufficient to induce specific necrosis in the presence of a matching Avr gene. Nevertheless, agroinfiltration of 35S-driven $C f$ genes in the absence of their matching $A v r$ genes did not result in necrosis. This may suggest that overproduction of $\mathrm{Cf}$ proteins is not toxic to the plant or that mechanisms exist that keep Cf protein levels sufficiently low. pCf dilution experiments also suggest that agroinfiltration of A. tumefaciens cultures that carry $C f$ genes with weak promoters should result in necrosis when expressed with their matching $A v r$ genes. Indeed, agroinfiltration of the $C f-9$ gene, driven by its native promoter, was found to induce necrosis when co-expressed with $A v r 9$ (data not shown).

\section{Comparison of $A v r 9 / C f$-9- and $A v r 4 / C f$-4-induced responses.}

Transient $C f$ gene expression allowed us for the first time to compare responses induced by different $A v r / C f$ gene pairs within the same leaf. We found that $A v r 9 / C f$-9-induced necrosis developed slower than Avr4/Cf-4-induced necrosis when pAvr- and pCf-containing cultures were combined in a $1: 1$ ratio. However, at concentrations of pAvr-containing cultures that correspond to $\mathrm{NC}^{50}$ values, no temporal differences between the two gene pairs were observed. This indicates that the temporal differences between Avr $9 / C f$-9- and Avr4/Cf-4induced responses are correlated with the activities of the pAvr constructs. These different pAvr activities can for example be due to differences in transcriptional or post-transcriptional modification, AVR protein stability, or perception. Comparison of different $A v r / C f$-induced responses in other systems has also indicated that the $A v r 9 / C f-9$ gene pair is less active than the Avr4/Cf-4 gene pair (M. H. A. J. Joosten, personal communication). For example, tomato seedlings die quicker when derived from seeds of a cross between Avr4 transgenic tomato and MM-Cf4 than when derived from seeds of a cross between Avr9 transgenic tomato and MM-Cf9.
Similarly, inoculation of PVX::Avr4 on MM-Cf4 results in a more severe systemic necrosis than inoculation of PVX::Avr9 on MM-Cf9 plants. Our results suggest that these temporal differences are due to differences between the Avr9 and Avr4 gene activities when expressed in planta, rather than to intrinsic differences between the function of $C f$ gene products.

\section{Presence of $A v r / C f$ signal transduction pathways in other plant families.}

The striking similarities between proteins encoded by $R$ genes cloned from different plant species suggest that different $R$ genes would function in other plant species. Indeed, the tomato Pto gene has been shown to function in Nicotiana spp. (Thilmony et al. 1995), the tobacco $N$ gene is active in tomato (Witham et al. 1996), and the tomato $C f-9$ gene is functional in potato and tobacco (Hammond-Kosack et al. 1998). We could extend this analysis by transient expression studies and show that $C f-9$ and $C f-4$ genes from tomato function in all Nicotiana spp. tested, as well as in Petunia hybrida. This indicates that the signal transduction pathway required for $A v r / C f$-mediated necrosis is conserved within the Solanaceae. It also suggests that these plant species may recruit the same signal transduction pathway to activate defense responses against their pathogens.

In contrast, $A$. thaliana, radish, lupine, pea, and flax did not show necrotic responses upon transient co-expression of matching $A v r / C f$ gene pairs, even though gus expression was detected and background responses were sufficiently low. This indicates that these plant species lack components that are required for $A v r / C f$-induced responses, implying that functional transfer of an $R$ gene from one plant family to another has its limitations.

An exception to the above is lettuce, a composite that seems to contain all components required for $A v r 4 / C f$-4-induced necrosis. This is the first report of an $R$ gene that can function in a different plant family. Surprisingly, Avr $9 / C f$-9-induced necrosis was not observed in lettuce, suggesting that the level of expression of $A v r 9$ in lettuce is below the threshold level that is required for activity. Alternatively, lettuce may lack one or more components of the signal transduction pathway required for $A v r 9 / C f$-9-induced necrosis.

\section{MATERIAL AND METHODS}

\section{Plant material, GUS staining, PVX inoculation, and protein preparations.}

Plants were grown under standard greenhouse conditions except for A. thaliana, which was grown under short day conditions. For most assays, 4- to 8-week-old N. tabacum cv. Petite Havana (SR1) plants were used, unless stated otherwise. 35S::Avr9-transgenic tobacco line SLJ6201A (HammondKosack et al. 1994) and transgenic tobacco line 6A3 carrying a genomic clone of $C f-9$ were used (Kamoun et al. 1999). GUS staining was performed as described by Jefferson (1987). PVX inoculations with wild-type PVX, PVX::Avr9, and PVX::Avr4 were performed as described before (Joosten et al. 1997; Hammond-Kosack et al. 1995). Synthetic AVR9 was prepared as described previously (Kooman-Gersmann et al. 1998). Apoplastic fluids were isolated from compatible $C$. fulvum-tomato interactions at 14 to 20 days after inoculation, as described by De Wit and Spikman (1982). 
DNA manipulations and plasmids.

All DNA manipulations were performed by standard protocols (Sambrook et al. 1989). Polymerase chain reaction (PCR) was performed with $P f u$ polymerase (Stratagene, La Jolla, CA), according to the manufacturer's instructions. Restriction enzymes, T4 ligase, and Escherichia coli DH5 $\alpha$ cells were from Life Technologies (Breda, The Netherlands). Primers were synthesized by Amersham-Pharmacia (Buckinghamshire, UK). Authenticity of all cloned PCR fragments was confirmed by sequencing.

The following plasmids were used in our studies: pFM4 and pMOG800 (Honée et al. 1998), pCf9.5 (prpl::Cf-9, pMOG1048; Honée et al. 1998), pGUSi (Fig. 1; pMOG410; Hood et al. 1993), PVX::Avr4 (Thomas et al. 1997), and pAvr9 (Fig. 1; pMOG978; Honée et al. 1998). pFT43, containing a $C f-4$ genomic clone, was kindly provided by Frank Takken (Department of Genetics, BioCentrum Amsterdam; Takken 1999).

pCf9 and pCf4 were constructed as follows: with $\mathrm{XbaI}$ and NcoI restriction sites, the $35 \mathrm{~S}$ promoter from pFM4 was cloned into pCf9.5, thereby replacing the prpl promoter and creating pRH1. The $5^{\prime}$ part of the $C f-4$ gene was amplified from pFT43, with primers ttagtgcagccatgggttgtg and catgcaacttatttgatctcaagc ( $\mathrm{NcoI}$ site is underlined). The latter primer anneals $3^{\prime}$ of the HindIII site, which is present in both $C f-9$ and $C f-4$. With $N c o$ I and HindIII restriction sites, the PCR product was cloned into pRH1, thereby replacing the $5^{\prime}$ terminal part of $C f-9$ with that of $C f-4$, generating pRH46. The $3^{\prime}$ region of the HindIII restriction site of $C f-9$ and $C f-4$ genes encodes identical amino acids. The promoter-ORF-terminator cassettes of pRH1 and pRH46 were subsequently transferred to pMOG800 with BamHI and KpnI restriction sites, creating binary plasmids pCf9 (pRH21) and pCf4 (pRH48).

For the construction of pAvr4, the $35 \mathrm{~S}$ promoter was amplified from $\mathrm{pRH} 1$ with primers gatctctagaggtcaacatggtggagcacg and aaaactgcagctcgaggtcgacaccatggtattgtaaatagtaattgtaatgttg (XbaI, PstI, and NcoI sites are underlined, respectively) and cloned into pRH1 with $X b a \mathrm{I}$ and PstI. This construct (pRH80) carries the $35 \mathrm{~S}$ promoter and the PI-II terminator (An et al. 1989) flanking a multiple cloning site (NcoI-SalI-XhoI-PstI). The ORF encoding the mature AVR4 protein fused to the signal peptide of the pathogenesis-related gene PRla was amplified from PVX::Avr4 with primers cgttccactggagtcctttgg, ccaaaaggactccagtggaacg, ttagtgcagccatgggttgtg, and aaaactgcagtcattgcggcgtctttaccggacacg ( NcoI and PstI sites are underlined, respectively). The first two primers were designed to remove the PstI site from Avr4 by PCR overlap-extension. The PCR product was cloned into pRH80 with NcoI and PstI, thereby creating $\mathrm{pRH} 85$. The promoter-ORF-terminator cassette of pRH85 was cloned into pMOG800 with $\mathrm{XbaI}$ and EcoRI, creating the binary plasmid pAvr4 (pRH87).

\section{A. tumefaciens-mediated transient expression.}

The A. tumefaciens strain MOG101 (Hood et al. 1993) was transformed by electroporation. Recombinant A. tumefaciens containing the different binary plasmids was grown overnight $\left(28^{\circ} \mathrm{C}, 200 \mathrm{rpm}\right.$; LABOTECH RS500; Labotec, Belgium) in tubes containing $3 \mathrm{ml}$ of YEB medium (per liter: $5 \mathrm{~g}$ of beef extract [Sigma, St. Louis, MO], $1 \mathrm{~g}$ of yeast extract [Oxoid, Hampshire, UK], $5 \mathrm{~g}$ of bacteriological peptone [Oxoid], $5 \mathrm{~g}$ of sucrose, and $2 \mathrm{ml}$ of $1 \mathrm{M} \mathrm{MgSO}_{4}$ ) containing $50 \mu \mathrm{g}$ of ka- namycin (Duchefa, Haarlem, The Netherlands) per $\mathrm{ml}$ and 25 $\mu \mathrm{g}$ of rifampicin (Sigma) per ml. These cultures were used to inoculate a $300-\mathrm{ml}$ conical flask containing $100 \mathrm{ml}$ of YEB medium supplemented with $1 \mathrm{ml}$ of $1 \mathrm{M} \mathrm{N}$-morpholinoethanesulfonic acid (MES; Sigma), $50 \mu \mathrm{g}$ of kanamycin per $\mathrm{ml}$, and $2 \mathrm{mM}$ acetosyringone (Aldrich, Steinheim, Germany). After overnight incubation $\left(28^{\circ} \mathrm{C}, 200 \mathrm{rpm}\right.$; LABOTECH RS500; Labotec, Belgium), cells were harvested at an $\mathrm{OD}_{600}$ of 0.6 to 1.2 by centrifugation $\left(8^{\prime}, 4,000 \times g\right)$ and resuspended in MMA to a final OD of 2 (1 liter of MMA: $5 \mathrm{~g}$ of MS salts [Duchefa], $1.95 \mathrm{~g}$ of MES, $20 \mathrm{~g}$ of sucrose, $\mathrm{pH}$ adjusted to 5.6 with $1 \mathrm{M} \mathrm{NaOH}$ ], containing $200 \mu \mathrm{M}$ acetosyringone. At this stage, cultures were mixed as described in the figure legends. Cultures were infiltrated into leaves with a 2-ml disposable syringe without a needle. Leaves were superficially wounded with a needle to improve infiltration.

\section{ACKNOWLEDGMENTS}

We thank Rik Lubbers (Unifarm) for excellent plant care, Matthieu Joosten and Frank Takken for critically reading the manuscript, Guy Honée for useful suggestions, Tony van Kampen (Department of Molecular Biology, Wageningen University) for sequencing, Duotone for photography, Kim Hammond-Kosack (Sainsbury Laboratory, Norwich, UK) for Avr 9 transgenic tobacco plants, Colwyn Thomas (Sainsbury Laboratory, Norwich, UK) for PVX::Avr4 encoding N-terminally processed AVR4, Zeneca-Mogen (Leiden, The Netherlands) for Cf-9 transgenic tobacco plants and pMOG plasmids, and Paul Vossen for preparing apoplastic fluids. R. A. L. V. was supported by a grant from the Dutch Foundation for Earth and Life Sciences ALW, project number SLW 805.33-231. R. R. was supported by grants from the EMBO and the European Community (ERB4001GT97-2132), and F. L. was supported by a grant from the European Community (CHRX-CT93-0168).

\section{LITERATURE CITED}

Abbink, T. E. M., Tjernberg, P. A., Bol, J. F., and Linthorst, H. J. M. 1998. Tobacco mosaic virus helicase domain induces necrosis in $N$ gene-carrying tobacco in the absence of virus replication. Mol. PlantMicrobe Interact. 11:1242-1246.

An, G., Mitra, A., Choi, H. K., Costa, M. A., An, K., Thornburg, R. W., and Ryan, C. M. 1989. Functional analysis of the 3' control region of the potato wound-inducible proteinase inhibitor II gene. Plant Cell 1: 115-122.

Bendahmane, A., Kanyuka, K., and Baulcombe, D. C. 1999. The $R x$ gene from potato controls separate virus resistance and cell death responses. Plant Cell 11:781-791.

Bonas, U., and Van den Ackerveken, G. 1997. Recognition of bacterial avirulence proteins occurs inside the plant cell: a general phenomenon in resistance to bacterial diseases? Plant J. 12:1-7.

Bundock, P., and Hooykaas, P. 1998. Interactions between Agrobacterium tumefaciens and plant cells. Recent Adv. Phytochem. 32:207229.

Cai, D., Kleine, M., Kifle, S., Harloff, H. J., Sandal, N. N., Marcker, K. A., Klein-Lankhorst, R. M., Salentijn, E. M. J., Lange, W., Stiekema, W. J., Wyss, U., Grundler, F. M. W., and Jung, C. 1997. Positional cloning of a gene for nematode resistance in sugar beet. Science 275: 832-834.

Chapman, T., Kavanagh, T., and Baulcombe, D. 1992. Potato virus X as a vector for gene expression in plants. Plant J. 2:549-557.

Culver, J. N., Lindbeck, A. G. C., and Dawson, W. O. 1991. Virus-host interactions: Induction of chlorotic and necrotic responses in plants by tobamoviruses. Annu. Rev. Phytopathol. 29:193-217.

De Wit, P. J. G. M. 1997. Pathogen avirulence and plant resistance: A key role for recognition. Trends Plant Sci. 2:452-458.

De Wit, P. J. G. M., and Spikman, G. 1982. Evidence for the occurrence of race and cultivar-specific elicitors of necrosis in intercellular fluids of compatible interactions of Cladosporium fulvum and tomato. Physiol. Plant Pathol. 21:1-11. 
Erickson, F., Holzberg, S., Calderon-Urrea, A., Handley, V., Axtell, M., Corr, C., and Baker, B. 1999. The helicase domain of the TMV replicase proteins induces the $N$-mediated defence response in tobacco. Plant J. 18:67-75.

Frederick, R. D., Thilmony, R. L., Sessa, G., and Martin, G. B. 1998. Recognition specificity for the bacterial avirulence protein AvrPto is determined by Thr-204 in the activation loop of the tomato Pto kinase. Mol. Cell 2:241-245.

Hammond-Kosack, K. E., Harrison, K., and Jones, J. D. G. 1994. Developmentally regulated cell death on expression of the fungal avirulence gene $A v r 9$ in tomato seedlings carrying the disease-resistance gene $C f$ 9. Proc. Natl. Acad. Sci. USA 91:10445-10449

Hammond-Kosack, K. E., and Jones, J. D. G. 1996. Resistance gene dependent plant defence responses. Plant Cell 8:1773-1791.

Hammond-Kosack, K. E., Staskawicz, B. J., Jones, J. D. G., and Baulcombe, D. C. 1995. Functional expression of a fungal avirulence gene from a modified potato virus $\mathrm{X}$ genome. Mol. Plant-Microbe Interact. 8:181-185.

Hammond-Kosack, K. E., Tang, S., Harrison, K., and Jones, J. D. G. 1998. The tomato $C f-9$ disease resistance gene functions in tobacco and potato to confer responsiveness to the fungal avirulence gene product Avr9. Plant Cell 10:1251-1266.

Honée, G., Buitink, J., Jabs, T., De Kloe, J., Sijbolts, F., Apotheker, M., Weide, R., Sijen, T., Stuiver, M., and De Wit, P. J. G. M. 1998. Induction of defence-related responses in Cf9 tomato cells by the AVR9 elicitor peptide of Cladosporium fulvum is developmentally regulated. Plant Physiol. 117:809-820.

Hood, E. E., Gelvin, S. B., Melchers, L. S., and Hoekema, A. 1993. New Agrobacterium helper plasmids for gene transfer to plants. Transgenic Res. 2:208-218.

Jefferson, R. A. 1987. Assaying chimeric genes in plants: The GUS gene fusion system. Plant Mol. Biol. Rep. 5:387-405.

Jones, D. A., and Jones, J. D. G. 1997. The role of leucine-rich repeat proteins in plant defences. Adv. Bot. Res. 24:89-167.

Joosten, M. H. A. J., Cozijnsen, T. J., and De Wit, P. J. G. M. 1994. Host resistance to a fungal tomato pathogen lost by a single base-pair change in an avirulence gene. Nature 367:384-386.

Joosten, M. H. A. J., and De Wit, P. J. G. M. 1999. The tomatoCladosporium fulvum interaction: A versatile experimental system to study plant-pathogen interactions. Annu. Rev. Phytopathol. 37:335-367.

Joosten, M. H. A. J., Vogelsang, R., Cozijnsen, T. J., Verberne, M. C., and De Wit, P. J. G. M. 1997. The biotrophic fungus Cladosporium fulvum circumvents $C f$-4-mediated resistance by producing unstable AVR4 elicitors. Plant Cell 9:367-379.

Kamoun, S., Honée, G., Weide, R., Laugé, R., Kooman-Gersmann, M. de Groot, K., Govers, F., and De Wit, P. J. G. M. 1999. The fungal gene Avr 9 and the oomycete gene infl confer avirulence to potato virus X on tobacco. Mol. Plant-Microbe Interact. 12:459-462.

Kapila, J., De Rycke, R., Van Montagu, M., and Angenon, G. 1997. An Agrobacterium-mediated transient gene expression system for intact leaves. Plant Sci. 122:101-108.

Kooman-Gersmann, M., Vogelsang, R., Hoogendijk, E. C. M., and De Wit, P. J. G. M. 1997. Assignment of amino acid residues of the AVR9 peptide of Cladosporium fulvum that determine elicitor activity. Mol. Plant-Microbe Interact. 10:821-829.

Kooman-Gersmann, M., Vogelsang, R., Vossen, P., Van den Hooven, H. W., Mahé, E., Honée, G., and De Wit, P. J. G. M. 1998. Correlation between binding affinity and necrosis-inducing activity of mutant
AVR9 peptide elicitors. Plant Physiol. 117:609-618.

Laugé, R., and De Wit, P. J. G. M. 1998. Fungal avirulence genes: Structure and possible functions. Fung. Genet. Biol. 24:285-297.

Sambrook, J., Fritsch, E. F., and Maniatis, T. A. 1989. Molecular Cloning: A Laboratory Manual. 2nd ed. Cold Spring Harbor Laboratory, Cold Spring Harbor, NY.

Parker, J. E., and Coleman, M. J. 1997. Molecular intimacy between proteins specifying plant-pathogen recognition. Trends Biochem. Sci. 22:291-296.

Rathjen, J. P., Chang, J. H., Staskawicz, B. J., and Michelmore, R. W. 1999. Constitutively active Pto alleles induce a Prf-dependent hypersensitive response in the absence of AvrPto. EMBO J. 18:3232-3240.

Rossi, L., Escudero, J., Hojn, B., and Tinland, E. 1993. Efficient and sensitive assay for T-DNA-dependent transgene expression. Plant Mol. Biol. Rep. 11:220-229.

Scholtens-Toma, I. M. J., and De Wit, P. J. G. M. 1988. Purification and primary structure of a necrosis-inducing peptide from the apoplastic fluids of tomato infected with Cladosporium fulvum (syn. Fulvia fulva). Physiol. Mol. Plant Pathol. 33:59-67.

Scofield, S. R., Tobias, C. M., Rathjen, J. P., Chang, J. H., Lavelle, D. T., Michelmore, R. W., and Staskawicz, B. J. 1996. Molecular basis of gene-for-gene specificity in bacterial speck disease of tomato. Science 274:2063-2065.

Takken, F. L. W. 1999. The Cladosporium fulvum resistance locus Cf-4 of tomato. Isolation and characterisation. Ph.D. thesis. Vrije Universiteit, Amsterdam.

Tang, X., Frederick, R. D., Zhou, J., Halterman, D. A., Jia, Y., and Martin, G. B. 1996. Initiation of plant disease resistance by physical interaction of AvrPto and Pto kinase. Science 274:2060-2063.

Tang, X., Xie, M., Kim, Y. J., Zhou, J., Klessig, D. F., and Martin, G. 1999. Overexpression of Pto activates defence responses and confers broad resistance. Plant Cell 11:15-29.

Thilmony, R. L., Chen, S., Bressan, R. A., and Martin, G. B. 1995. Expression of the tomato Pto gene in tobacco enhances resistance to Pseudomonas syringae pv. tabaci expressing AvrPto Plant Cell 7: 1529-1537.

Thomas, C. N., Jones, D. A., Parniske, M., Harrison, K., Balint-Kurti, P. J., Hatzixanthis, K., and Jones, J. D. G. 1997. Characterisation of the tomato $C f$-4 gene for resistance to Cladosporium fulvum identifies sequences that determine recognitional specificity in $C f-4$ and $C f-9$. Plant Cell 9:2209-2224.

Van den Ackerveken, G., and Bonas, U. 1997. Bacterial avirulence proteins as triggers of plant disease resistance. Trends Microbiol. 5:394398

Van den Ackerveken, G., Marois, E., and Bonas, U. 1996. Recognition of the bacterial avirulence protein AvrBs3 occurs inside the host plant cell. Cell 87:1307-1316.

Van der Biezen, E. A., and Jones, J. D. G. 1998. Plant disease-resistance proteins and the gene-for-gene concept. Trends Biochem. Sci. 23:454456.

Vancanneyt, G., Schmidt, R., O'Connor-Sanchez, A., Willmitzer, L., and Rocha-Sosa, M. 1990. Construction of an intron-containing marker gene: Splicing of the intron in transgenic plants and its use in monitoring early events in Agrobacterium-mediated plant transformation. Mol. Gen. Genet. 220:245-250.

Witham, S. M., McCormick, S., and Baker, B. 1996. The $N$ gene of tobacco confers resistance to tobacco mosaic virus in transgenic tomato. Proc. Natl. Acad. Sci. USA 93:8776-8781. 